\title{
Growth in utero, adult blood pressure, and arterial compliance
}

\author{
C N Martyn, D J P Barker, S Jespersen, S Greenwald, C Osmond, C Berry
}

\begin{abstract}
Objectives-To examine the relation between disproportionate fetal growth and adult blood pressure and to investigate whether arterial compliance in adult life is related to early development.
\end{abstract}

Design-A follow up study of a group of men and women whose birth weights and other measurements of body size had been recorded at birth.

Setting-Home and outpatient study. Subjects-337 men and women born in the Jessop Hospital, Sheffield, between 1939 and 1940.

Main outcome-Adult systolic and diastolic blood pressures and arterial compliance as measured by pulse wave velocity in two arterial segments.

Results-Both systolic and diastolic blood pressures were higher in people whose birth weight was low, who were short or who had small abdominal or head circumferences at birth. Systolic blood pressure decreased by $2.7 \mathrm{~mm} \mathrm{Hg}$ $(95 \% \mathrm{CI} 0.8$ to 4.6$)$ for each pound ( $454 \mathrm{~g})$ gain in birth weight and by $3.4 \mathrm{~mm} \mathrm{Hg}$ $(95 \% \mathrm{CI} 1.4$ to 5.4$)$ for each inch $(2.54 \mathrm{~cm})$ increase in crown-heel length. Diastolic pressure fell by $1.9 \mathrm{~mm} \mathrm{Hg}(95 \%$ CI 0.9 to $2.9)$ for each pound (454 $\mathrm{g}$ ) gain in birth weight and by $2.4 \mathrm{~mm} \mathrm{Hg}(95 \%$ CI 1.4 to 3.5) for each inch $(2.54 \mathrm{~cm})$ increase in length. Systolic blood pressure was also higher in individuals whose mother's intercristal pelvic diameter was small or whose mother's blood pressure had been raised during pregnancy but these effects were statistically independent of the effects of low birth weight and other measurements that indicate fetal growth retardation. Arterial compliance was lower in those who had been small at birth.

Conclusion-Impairment of fetal growth is associated with raised blood pressure in adult life and decreased compliance in the conduit arteries of the trunk and legs.

\section{(Br Heart f 1995;73:116-121)}

Keywords: fetal growth, adult arterial compliance, adult blood pressure.

Several studies have shown that low birth weight is associated with raised blood pressure in both childhood and adult life and with an increased risk of death from cardiovascular disease. ${ }^{1-5}$ This suggests that the pathophysiological mechanisms that ultimately lead to arterial disease are initiated in utero. A recent analysis of a longitudinal study of children and three follow up studies of adults indicated that the relation between birth weight and current blood pressure becomes stronger with increasing age. ${ }^{6}$ This observation is compatible with Folkow's hypothesis ${ }^{7}$ that the pathogenesis of hypertension requires both an initiating process and a subsequent progressive amplification.

The mechanisms that initiate and amplify blood pressure may have their origin in fetal development and could involve modification of arterial structure. ${ }^{89} \mathrm{~A}$ short period of hypertension in young animals induces irreversible alterations in the mechanical properties of the arterial wall ${ }^{10}$ and it has been shown experimentally that DNA content of the rat aorta is affected by growth inhibition during fetal development. ${ }^{11}$ In infants born with a single umbilical artery, the common iliac artery that gave rise to it is elastic while the other, in which blood flow was lower, is thin walled and muscular. Measurements of arterial compliance in children born with a single umbilical artery at ages between 5 and 8 years show that the iliac artery on the side of the single umbilical artery remains more elastic. ${ }^{12}$ Arterial compliance determines pulse pressure and changes in pulse pressure stimulate structural modifications in the vessel wall that, in turn, affect arterial compliance. ${ }^{913}$ This is one possible mechanism by which adaptations in the fetal pattern of circulation could alter the structure of blood vessels in a way that leads to the perpetuation and amplification of raised blood pressure from infancy to old age.

The present study had two aims. The first was to examine the relation between fetal growth and adult levels of blood pressure in a group of people now aged 50-53 years who had been measured in unusual detail at birth and whose mothers' blood pressure during pregnancy had also been recorded. The second was to investigate whether arterial compliance is related to fetal growth retardation and whether this might provide a mechanism by which the initiating pressor effects of retarded fetal growth could be sustained and amplified throughout adult life.

\section{Patients and methods}

At the Jessop Hospital for Women, Sheffield, a standard form was used to enter details of each mother and infant. The information recorded included the date of the mother's last menstrual period and the intercristal (distance between iliac crests) and external conjugate (distance from the symphysis pubis 
to the fifth lumbar vertebra) diameters of her pelvis and her blood pressure which was measured from two to 15 times during the pregnancy. The baby's birth weight was recorded in both pounds and grams. Its length, head and abdominal circumferences were measured in inches. The weight of the placenta was noted in grams.

We used the National Health Service Central Register to trace 1039 singleton infants who were born in the hospital to married mothers between 1939 and 1940 and whose records were complete. Some 419 were still living in Sheffield. After obtaining permission from their general practitioners, we wrote to them asking whether we might visit and interview them in their homes. A total of 337 $(80 \%)$ agreed and were subsequently seen by one of four fieldworkers. Each fieldworker, who had not seen the data concerning the person's birth, administered a questionnaire which inquired about current medication, smoking habits and alcohol consumption. They also measured height with a portable stadiometer and weight with a portable Seca scale. Blood pressure and pulse rate were measured twice in the right arm with a Dinamap automated recorder with the subjects seated. The cuff was removed and replaced between measurements. Room temperature was also recorded. One woman completed the questionnaire but declined to have her blood pressure measured. The average of the two blood pressure readings was used in the analysis. The procedures for taking all measurements were standardised and the fieldworkers trained before starting the study. A check, after the training period, in which repeated measurements were made on subjects selected from outside the study population, revealed no significant interobserver variation. The subject's social class at birth was defined from the father's occupation and current social class derived from their own or their husband's occupation.

After the interview, the subjects were invited to the Northern General Hospital, Sheffield. Two hundred and thirty five agreed to attend. At this clinic visit arterial compliance was measured by a non-invasive optical method ${ }^{14}$ that determines the transit time of the wave of dilatation propagating in the arterial wall, as a result of the pressure wave generated by con-

Table 1 Mean birth measurements and duration of gestation in men and women born in Sheffield between 1939 and 1940 and percentages according to social class

\begin{tabular}{|c|c|c|c|}
\hline & $\begin{array}{l}\text { Men } \\
(n=170)\end{array}$ & $\begin{array}{l}\text { Women } \\
(n=167)\end{array}$ & $S D$ \\
\hline $\begin{array}{l}\text { Birth measurements: } \\
\text { Birth weight (oz) } \\
\text { Length (in) } \\
\text { Head circumference (in) } \\
\text { Abdominal circumference (in) } \\
\text { Placental weight (g) }\end{array}$ & $\begin{array}{r}116.8 \\
20.0 \\
13.6 \\
12.4 \\
621.4\end{array}$ & $\begin{array}{r}112.0 \\
19.9 \\
13.4 \\
12.3 \\
623.7\end{array}$ & $\begin{array}{c}18 \cdot 0 \\
1.0 \\
0.67 \\
1.1 \\
114.1\end{array}$ \\
\hline Duration of gestation & $40 \cdot 3$ & $40 \cdot 4$ & $2 \cdot 0$ \\
\hline $\begin{array}{l}\text { Percent social classes IV and } V \text { at birth } \\
\text { Percent social classes IV and } V \text { currently }\end{array}$ & $\begin{array}{l}38 \cdot 2 \\
20 \cdot 6\end{array}$ & $\begin{array}{l}34 \cdot 7 \\
19 \cdot 8\end{array}$ & \\
\hline
\end{tabular}

One ounce is equivalent to $28 \mathrm{~g}$; 1 inch is equivalent to $2.54 \mathrm{~cm}$. traction of the left ventricle. Measurement of the time taken for the wave to travel a known distance allows the velocity of the pulse wave to be calculated. The method yields results similar to those obtained by a technique based on Doppler ultrasonography that has been shown to give reproducible estimates of arterial compliance in population studies. ${ }^{15}$ The optical method has been validated against intraarterial determinations of pressure wave velocity. Pulse wave velocities were measured in two arterial segments: an aorto-iliac segment that extended from the proximal part of the common carotid artery near the arch of the aorta into the femoral artery just below the inguinal ligament, and a femoro-poplitealtibial segment from the femoral artery at the inguinal ligament to the posterior tibial artery immediately posterior to the medial malleolus or the dorsalis pedis artery. In some subjects it was not possible to obtain recordings of the pulse wave of adequate quality. This was usually because of subcutaneous fat that attenuated the transmission of the optical signal used to detect arterial dilatation or because of difficult access to the position of the arteryparticularly to the carotid artery in the root of the neck. Estimations of pulse wave velocity based on fewer than 10 cardiac cycles or those in which the coefficient of variation of arterial transit times was greater than $30 \%$ were rejected. Pulse wave velocity is inversely related to the square root of the compliance of the vessel wall. High pulse wave velocity therefore indicates a stiffer arterial wall. Blood pressure was measured in the right brachial artery immediately after each measurement of pulse wave velocity.

\section{STATISTICAL METHODS}

We used multiple linear regression and tabulation of means to examine the relation between measurements of body size at birth, adult blood pressure, and pulse wave velocity. The frequency distribution of pulse wave velocities was skewed and a reciprocal square root transformation was used to make it more symmetrical in regression analyses of this variable. Blood pressure was higher in men than in women, and in people with a high body mass index and in those who drank alcohol. Blood pressure tended to be lower in those people who had been born before 38 weeks of completed gestation. Adjustment has been made for these factors by regression.

Birth weight, length, and head circumference were divided into groups in the same way as in our previous studies. ${ }^{3-5}$ Categories of abdominal circumference were chosen so that there were approximately the same number of babies in each of the four groups. The mean value of several recordings of maternal blood pressure during pregnancy was used during analysis of this variable. For clarity of presentation, we have shown the results as tables of mean values of blood pressure and pulse wave velocity within each group of birth measurements. Values for pulse wave velocity were transformed back to the original units of measurement in these tables. All values given 


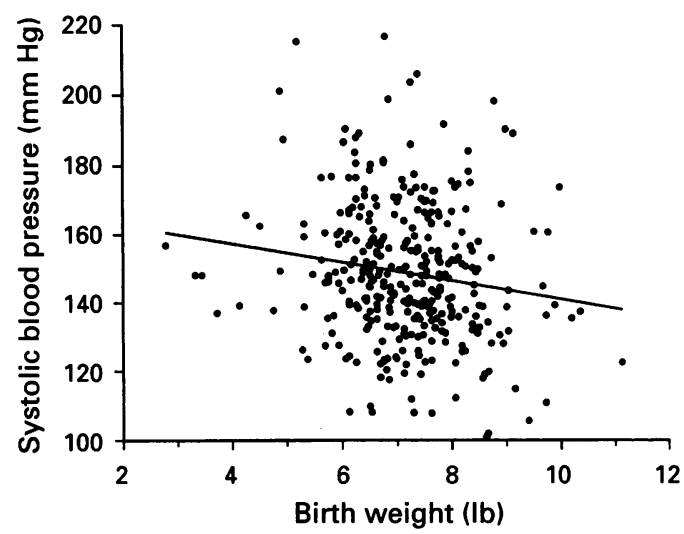

Figure 1 Scatterplot of systolic blood pressure $(\mathrm{mm} \mathrm{Hg})$ adjusted for sex, body mass index, alcohol intake and gestational age according to birthweight (lb).

for statistical significance were calculated by regression with maternal and birth measurements used as continuous and not categorical variables.

\section{Results}

Table 1 shows the mean birth weight and other measurements of body size of the 337

Table 2 Mean systolic and diastolic blood pressures adjusted for sex, current body mass index, alcohol intake and gestational age, according to measurements made during pregnancy and at birth

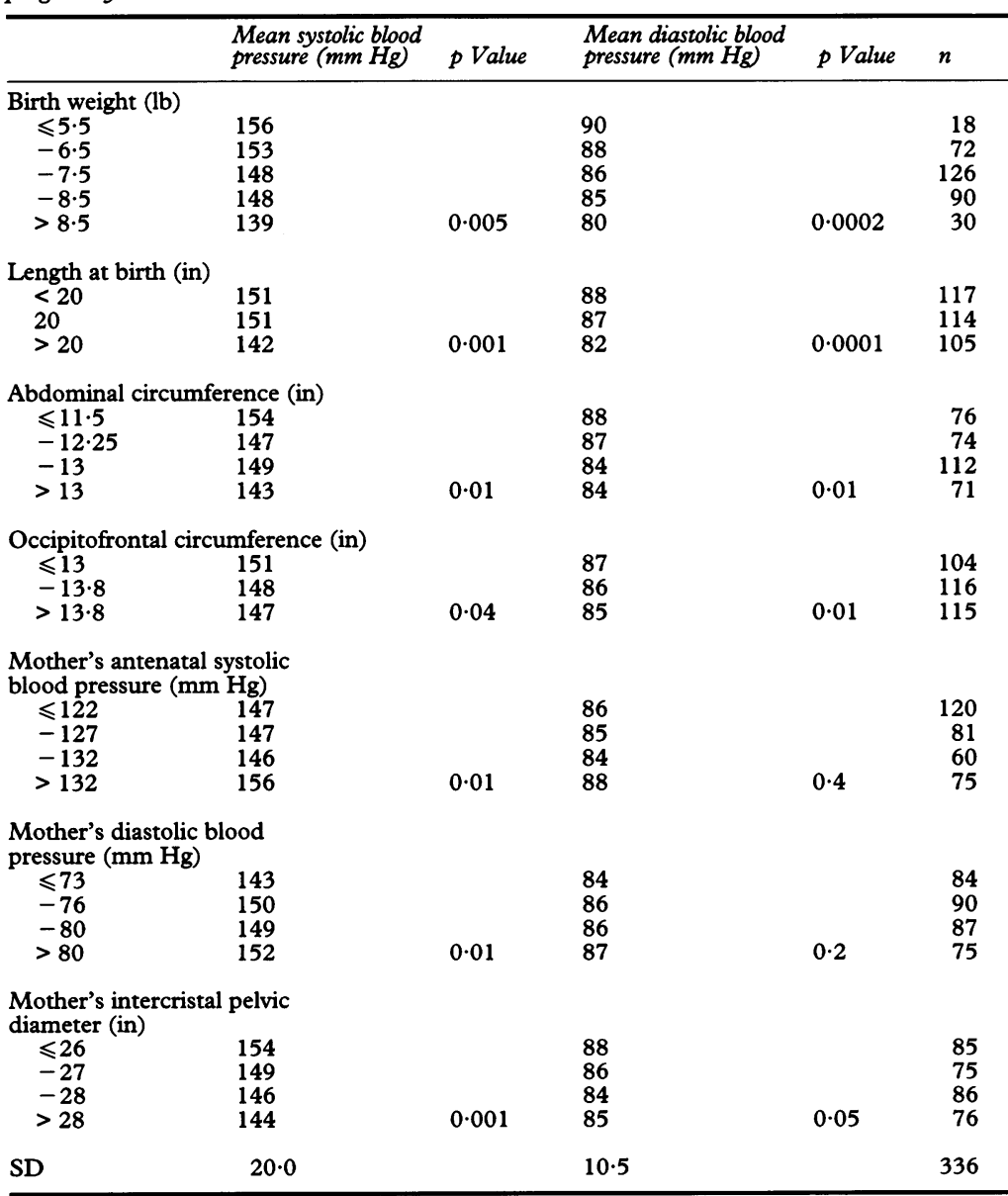

One pound is equivalent to $454 \mathrm{~g}$; 1 inch is equivalent to $2.54 \mathrm{~cm}$. Because of missing values in the birth records, numbers in different categories of maternal and infant measurement vary slightly.

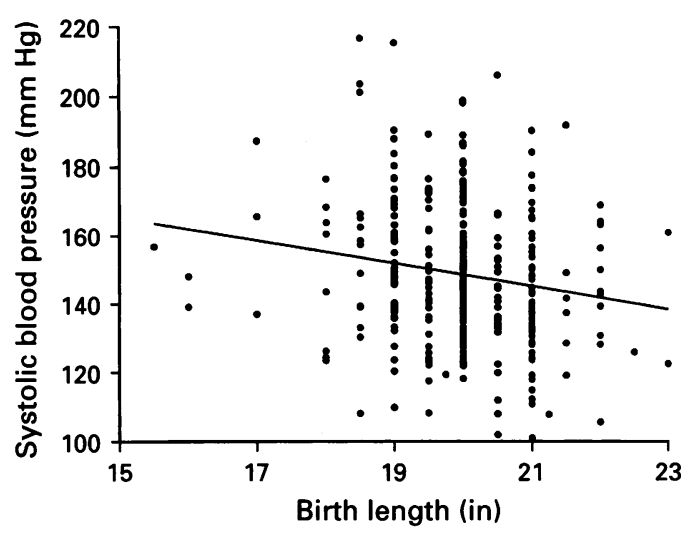

Figure 2 Scatterplot of systolic blood pressure $(\mathrm{mm} \mathrm{Hg})$ adjusted for sex, body mass index, alcohol intake and gestational age according to length at birth (in). Values for length are clumped because measurements were recorded to the nearest half inch.

people who were interviewed at home. Some 235 of them $(70 \%)$ subsequently attended a clinic for measurement of arterial compliance. There were no statistically significant differences in any of the birth measurements between those who agreed to attend the clinic and those who declined.

\section{BLOOD PRESSURE}

In the 336 subjects whose blood pressure was measured, systolic pressure was $11 \mathrm{~mm} \mathrm{Hg}$ higher in men than in women and mean diastolic pressure $7 \mathrm{~mm} \mathrm{Hg}$ higher. In both sexes systolic and diastolic blood pressures were higher in those with a high body mass index and among those with a moderate or high alcohol intake. Mean systolic pressure was $17 \mathrm{~mm} \mathrm{Hg}$ higher and mean diastolic pressure $8 \mathrm{~mm} \mathrm{Hg}$ higher in those whose body mass index was greater than 28 compared with those whose body mass index was 24 or less. In individuals who drank moderate or large amounts of alcohol (21 units per week or more for men; 14 units per week or more for women) mean systolic pressure was $160 \mathrm{~mm} \mathrm{Hg}$ and mean diastolic pressure $92 \mathrm{~mm} \mathrm{Hg}$ compared with $146 \mathrm{~mm} \mathrm{Hg}$ and $85 \mathrm{~mm} \mathrm{Hg}$ in people who drank less. Twenty eight subjects were born before 38 weeks of completed gestation; the mean systolic pressure of this group was $142 \mathrm{~mm} \mathrm{Hg}$ and the mean diastolic pressure $83 \mathrm{~mm} \mathrm{Hg}$ compared with $150 \mathrm{~mm} \mathrm{Hg}$ and $86 \mathrm{~mm} \mathrm{Hg}$ for those born after 38 weeks. Blood pressures were not consistently related to social class either at birth or currently, to smoking habit, or to room temperature. Even without adjustment for these variables, systolic and diastolic blood pressures were higher in people who had lower birth weight, who had been shorter at birth, or who had smaller abdominal or head circumferences at birth. These trends were present in both sexes. Adjustment of systolic and diastolic blood pressures for current body mass index, alcohol intake, sex, and gestational age increased the strength of the relation with birth measurements present before adjustment. After adjustment, mean systolic pressures were $17 \mathrm{~mm} \mathrm{Hg}$ higher and mean 
Table 3 Mean systolic blood pressure adjusted for sex, body mass index, alcohol intake and gestational age according to length at birth and mother's pelvic diameter

\begin{tabular}{lrrrrrr}
\hline \multicolumn{7}{c}{ Mother's intercristal pelvic diameter (in) } \\
\cline { 2 - 7 } & $\leqslant 26$ & -27 & -28 & $>28$ & All & $n$ \\
\hline \multicolumn{7}{l}{ Infant's length at birth (in) } \\
$<20$ & 167 & 153 & 149 & 141 & 154 & 69 \\
20 & 153 & 153 & 149 & 157 & 153 & 81 \\
$>20$ & 148 & 147 & 137 & 132 & 141 & 61 \\
All & 158 & 151 & 146 & 144 & 150 & \\
$n$ & 57 & 49 & 80 & 45 & & \\
\hline
\end{tabular}

One inch is equivalent to $2.54 \mathrm{~cm}$.

diastolic pressures $10 \mathrm{~mm} \mathrm{Hg}$ higher in those whose birth weight had been less than $5.5 \mathrm{lb}$ $(2497 \mathrm{~g})$ compared with those who had weighed more than $8.5 \mathrm{lb}$ (3859 g). People whose crown-heel length had been less than 20 in $(50.8 \mathrm{~cm})$ had mean systolic and diastolic pressures $9 \mathrm{~mm} \mathrm{Hg}$ and $6 \mathrm{~mm} \mathrm{Hg}$ higher than those whose length at birth exceeded 20 in $(50.8 \mathrm{~cm})$. The relation between length at birth and adult blood pressure is at least as strong as the relation between birth weight and adult blood pressure. Figures 1 and 2 and table 2 show these results.

The mother's blood pressure, both systolic and diastolic, during pregnancy and the size of her pelvis, as reflected by the intercristal

Table 4 Mean systolic and diastolic blood pressures adjusted for sex, current body mass index and alcohol intake according to measurements made during pregnancy and at birth for infants born between 38 and 41 weeks of completed gestation

\begin{tabular}{|c|c|c|c|c|c|}
\hline & $\begin{array}{l}\text { Mean systolic } \\
\text { blood pressure } \\
\text { (mm Hg) }\end{array}$ & p Value & $\begin{array}{l}\text { Mean diastolic } \\
\text { blood pressure } \\
\text { ( } m m \mathrm{Hg})\end{array}$ & p Value & $n$ \\
\hline $\begin{array}{l}\text { Birth weigh } \\
\quad \leqslant 5.5 \\
-6.5 \\
-7.5 \\
-8.5 \\
>8.5\end{array}$ & $\begin{array}{l}171 \\
156 \\
149 \\
148 \\
141\end{array}$ & 0.0005 & $\begin{array}{l}95 \\
90 \\
87 \\
85 \\
81\end{array}$ & 0.0001 & $\begin{array}{r}8 \\
47 \\
84 \\
60 \\
21\end{array}$ \\
\hline $\begin{array}{l}\text { Length at } b \\
<20 \\
20 \\
>20\end{array}$ & $\begin{array}{l}154 \\
153 \\
143\end{array}$ & 0.0001 & $\begin{array}{l}90 \\
88 \\
82\end{array}$ & 0.0001 & $\begin{array}{l}69 \\
86 \\
65\end{array}$ \\
\hline $\begin{array}{c}\text { Abdominal } \\
\leqslant 11 \cdot 5 \\
-12 \cdot 25 \\
-13 \\
>13\end{array}$ & $\begin{array}{l}\text { nce (in) } \\
160 \\
148 \\
150 \\
146\end{array}$ & 0.002 & $\begin{array}{l}91 \\
86 \\
85 \\
85\end{array}$ & 0.001 & $\begin{array}{l}45 \\
52 \\
74 \\
47\end{array}$ \\
\hline $\begin{array}{l}\text { Occipitofro } \\
\leqslant 13 \\
\leqslant 13 \cdot 8 \\
>13.8\end{array}$ & $\begin{array}{l}\text { ference (in) } \\
153 \\
150 \\
149\end{array}$ & $0 \cdot 06$ & $\begin{array}{l}88 \\
87 \\
86\end{array}$ & 0.02 & $\begin{array}{l}66 \\
80 \\
73\end{array}$ \\
\hline $\begin{array}{c}\text { Mother's ar } \\
\leqslant 122 \\
-127 \\
-132 \\
>132\end{array}$ & $\begin{array}{l}\text { tolic blood pre } \\
147 \\
149 \\
148 \\
158\end{array}$ & $\mathrm{re}(\mathrm{mm} \mathrm{H}$ & $\begin{array}{l}86 \\
86 \\
86 \\
90\end{array}$ & $0 \cdot 2$ & $\begin{array}{l}74 \\
51 \\
39 \\
56\end{array}$ \\
\hline $\begin{array}{l}\text { Mother's d } \\
\leqslant 73 \\
-76 \\
-80 \\
>80\end{array}$ & $\begin{array}{l}\text { d pressure (mr } \\
142 \\
150 \\
153 \\
157\end{array}$ & 0.0001 & $\begin{array}{l}86 \\
86 \\
86 \\
86\end{array}$ & $0 \cdot 2$ & $\begin{array}{l}52 \\
61 \\
58 \\
49\end{array}$ \\
\hline $\begin{array}{l}\text { Mother's in } \\
\leqslant 26 \\
-27 \\
-28 \\
>28\end{array}$ & $\begin{array}{l}\text { elvic diameter } \\
158 \\
151 \\
146 \\
144\end{array}$ & 0.001 & $\begin{array}{l}88 \\
86 \\
85 \\
85\end{array}$ & 0.03 & $\begin{array}{l}57 \\
49 \\
60 \\
45\end{array}$ \\
\hline SD & $21 \cdot 2$ & & 10.5 & & 220 \\
\hline
\end{tabular}

One pound is equivalent to $454 \mathrm{~g}$; 1 inch is equivalent to $2.54 \mathrm{~cm}$. Because of missing values in the birth records, numbers in different categories of maternal and infant measurement vary slightly. diameter, influenced the adult blood pressure of her offspring. Those whose mothers had higher blood pressure when pregnant or whose mother's intercristal pelvic diameter was small tended to have higher blood pressure themselves (table 2). When analysed in regression models simultaneously with either birth weight or length at birth or head or abdominal circumference at birth, both maternal pelvic size and antenatal blood pressure had statistically significant effects on adult blood pressure that were independent of the effects of the birth measurements. The regression coefficients of weight, length, and abdominal and head circumferences at birth on adult blood pressure and their statistical significance were little altered by the addition of these maternal variables to the regression model. Table 3 shows the independence of the effects of maternal pelvic size and maternal blood pressure during pregnancy from those effects associated with measurements of the infant at birth. Regardless of the mother's intercristal pelvic diameter, shorter infants had higher adult systolic blood pressure. Similarly, at any particular length, infants whose mothers' intercristal diameters were large tended to have lower blood pressure in adult life.

No consistent relations between adult blood pressure and placental weight or ponderal index (weight/length ${ }^{3}$ ) of the infant for either systolic or diastolic pressure were found.

Because the proportionate relations of head circumference, length, abdominal circumference, and birth weight differ between infants born at term and those born prematurely or postmaturely, the relations between current blood pressure and indicators of poor fetal growth might have been distorted by the inclusion of groups of babies born before 38 weeks or after 41 weeks of completed gestation. Table 4 shows systolic and diastolic blood pressures according to measurements made at birth in the subset of subjects born between 38 and 41 weeks of gestational age. Despite smaller numbers, the relations between adult blood pressure and smallness at birth persist and the trends are statistically stronger.

ARTERIAL COMPLIANCE

We measured transit times of the blood flow pressure wave in aorto-iliac and femoropopliteal-tibial arterial segments. It was not possible to obtain recordings of satisfactory quality for both segments from every subject. Twenty seven $(12 \%)$ of the measurements from the aorto-femoral segment and $14(6 \%)$ of those from the femoro-popliteal-tibial segment were rejected using criteria described under methods. The birth measurements of those from whom it was impossible to obtain adequate recordings of pulse wave velocity were similar to those of the group as a whole. There were no statistically significant differences between sexes and the results for men and women were analysed together. Pulse wave velocities in aorto-iliac and femoro-popliteal-tibial arterial segments were 
Table 5 Mean pulse wave velocity in aorto-iliac and femoro-popliteal-tibial arterial segments according to measurements made at birth

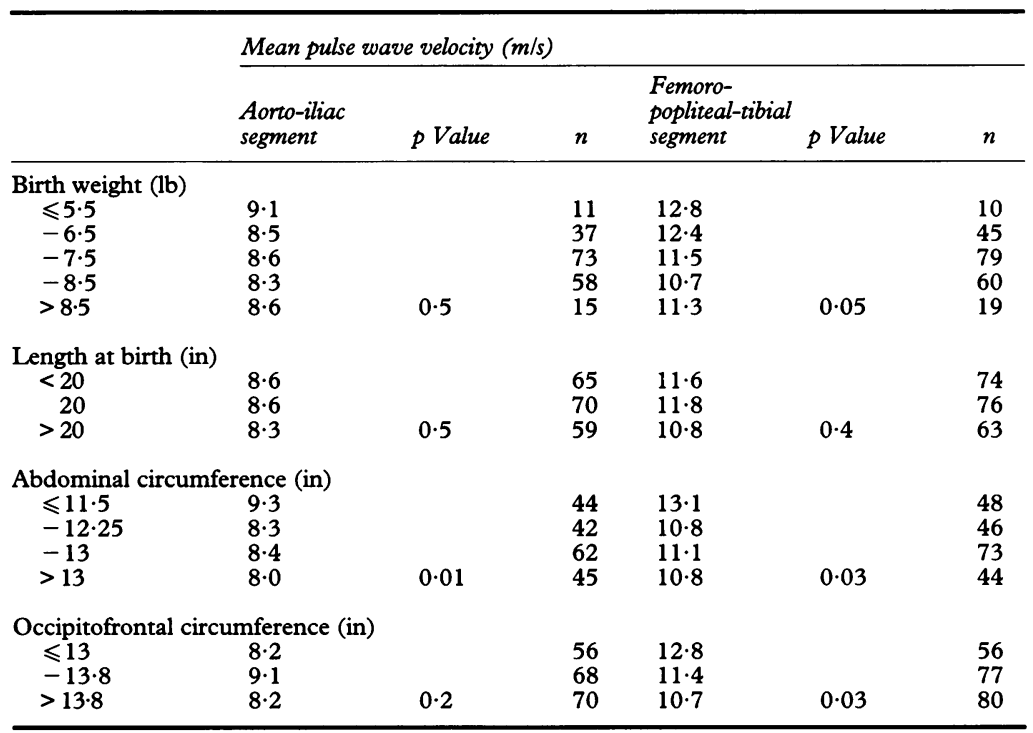

One pound is equivalent to $454 \mathrm{~g} ; 1$ inch is equivalent to $2.54 \mathrm{~cm}$.

unrelated to social class, either currently or at birth, or to adult height or weight.

Pulse wave velocities in the aorto-iliac segment tended to be higher in people who had been light or short or who had a smaller abdominal circumference at birth (table 5). Although consistent in direction, with a decrease in a birth measurement being associated with increased pulse wave velocity, the trends are weak and none was statistically significant. The relations between pulse wave velocities in the femoro-popliteal-tibial segment and birth measurements are similar in direction but stronger (table 5). Smallness in other birth measurements, whether length or abdominal or head circumference, was also associated with increasing pulse wave velocity (table 5). The relation between pulse wave velocity in the femoro-popliteal-tibial arterial segment and birth weight, or abdominal or head circumference was statistically significant.

Pulse wave velocity in both arterial segments was related to the level of systolic blood pressure recorded immediately after the pulse wave measurements (table 5 ). The relation between pulse wave velocity and birth measurements is not greatly affected by taking account of current blood pressure. Inclusion of systolic blood pressure in a multiple regression analysis did not alter the statistical significance of the relations between pulse wave velocity and birth weight or other birth measurements shown in table 5 .

We found no relation between pulse wave velocity in either arterial segment and ponderal index at birth or placental weight. Nor was there a relation with maternal blood pressure in pregnancy or any measure of maternal pelvic size.

\section{Discussion}

We found that both systolic and diastolic blood pressures in men and women now aged around 50 years were related to indicators of fetal growth retardation. These results are consistent with those of several previous studies in which associations between systolic blood pressure and birth weight have been reported. ${ }^{124}$ In most previous studies, birth weight has been the only measurement of fetal growth available. Here, we have been able to show that raised blood pressure is also related to both shortness and small abdominal circumference at birth. Pulse wave velocity, a variable that is inversely related to the compliance of the arterial wall in aorto-iliac and femoro-popliteal-tibial arterial segments, was greatest in subjects whose measurements indicated that they were small at birth.

The subjects in this study were born in hospital at a time when many births took place at home and they have continued to live in the town in which they were born. They are not therefore representative of all people born in Sheffield. However, our analyses are based on comparisons within the sample and unless the relations of blood pressure, arterial compliance and fetal growth are different among people born in and outside hospital and between migrants and non-migrants, no bias will have been introduced. The associations between measurements made at birth, adult blood pressure and arterial compliance were independent of variables associated with adult lifestyle, including social class, cigarette smoking, consumption of alcohol and obesity. Differences in levels of systolic and diastolic blood pressure over the ranges of weight, length and abdominal circumference at birth were as large as those over the range of current body mass indices or alcohol consumption.

The associations of raised adult blood pressure with small measurements at birth are not the result of shortened gestation. When the analysis was confined to the subgroup of infants born at term the associations between blood pressure and weight, or length, or abdominal circumference at birth become stronger than in the sample as a whole (table 4). This indicates that the associations depend on reduced fetal growth and not premature birth.

Two maternal factors, size, as indicated by intercristal pelvic diameter, and blood pressure during pregnancy were related to adult blood pressure. Mothers who were small or whose blood pressure was high antenatally tended to have offspring whose blood pressure was raised. These effects do not seem to be mediated through associations with size at birth as, in a simultaneous analysis, the regression coefficients associated with maternal size, blood pressure and infant's size at birth are little changed and remain statistically significant after the inclusion of birth weight or other birth measurements. Table 3 shows that although maternal size influences the adult blood pressure of her offspring, the association between length at birth and adult blood pressure is independent of this effect.

Apart from weight, length and abdominal circumference at birth are the measurements most strongly associated with adult blood 
pressure. The relation between head circumference at birth and adult blood pressure is weaker. In late gestation the human fetus may respond to nutrient deprivation by maintaining the brain at the expense of growth of the trunk. ${ }^{1516}$ The association of blood pressure with length and abdominal circumference at birth suggests that one way in which retarded fetal growth can lead to hypertension in adult life depends on undernutrition in the later stages of gestation.

In a previous study of adults in Preston, adult systolic blood pressure was related to thinness at birth, as indicated by a low ponderal index, in those babies with placental weights of $1.25 \mathrm{lb}(567.5 \mathrm{~g})$ or less. ${ }^{17} \mathrm{We}$ found no similar relation in the present study. Low ponderal index is thought to be an indication of retarded fetal growth in the midtrimester of pregnancy. It is possible that the lack of a relation between blood pressure and low ponderal index in Sheffield reflects the fact that few subjects in Sheffield had fetal growth retardation of this type. Comparison of birth measurements in the two towns shows that while infants born in Sheffield were, on average, heavier at birth and had larger heads, they were shorter than those born in Preston. The mean ponderal index of the Sheffield infants was 14.4 compared with 13.2 in those from Preston.

The results of this study in Sheffield conflict with those of the study in Preston in one other respect. In Preston there was a strong inverse relation between adult systolic blood pressure and placental weight. ${ }^{4}$ No such relation was found in the present study. Because undernutrition in pregnancy can either constrain or stimulate placental growth, depending on its timing and severity, the presence and strength of an association between adult blood pressure and placental weight is likely to vary from one population to another. ${ }^{18}$

The mechanisms by which retarded fetal growth leads to raised blood pressure in adult life are not known. Our results suggest that reduced arterial compliance may be involved. Reduced compliance is known to contribute to the pathogenesis of hypertension; it has also been linked to cardiac hypertrophy. ${ }^{13}{ }^{19} \mathrm{At}$ any mean arterial pressure, a reduction in compliance of the large arteries leads to an increase in pulse pressure and therefore accentuates the systolic afterload of the left heart. ${ }^{9}$ Compliance in the carotid femoral arterial segment has been shown to correlate with left ventricular mass/volume ratio in normal and hypertensive subjects. ${ }^{20}$

Intrauterine growth retardation is associated with altered Doppler blood flow velocity waveforms in several vascular beds, including the descending aorta and cerebral vasculature..$^{21} 23$ These changes are the result of selective modification of peripheral vascular resistance in the fetus leading to preferential perfusion of the brain at the expense of the trunk. Observations in infants born with a single umbilical artery indicate that structural adaptations in the walls of large arteries occur in response to alteration in blood flow and that these adaptations persist for several years. ${ }^{12}$ Decreased blood flow in the descending aorta and the arteries of the lower limb in fetuses with growth retardation may initiate changes in arterial structure that, in the long term, contribute to the maintenance of raised blood pressure and the pathogenesis of cardiac hypertrophy. We thank all the men and women who gave their time to
participate in the study, to the medical records department participate in the study, to the medical records department
at the Jessop Hospital, Sheffield who preserved the records and allowed us to use them, to the staff of the NHS Central Register, Southport and the Sheffield Family Health Register, Southport and the Sheffield Family Health
Services Authority who helped locate the subjects, and to Services Authority who helped locate the subjects, and to
Professor N Read who allowed us to hold clinics in his department. Kate Ellis, Catherine Laughton, Rachel Strong, and Catherine Williams carried out the fieldwork. Graham Wield was responsible for data processing. The study was funded by the Medical Research Council, the Wellcome Trust, and Children Nationwide.

1 Barker DJP, Osmond C, Golding J, Kuh D, Wadsworth MEJ. Growth in utero, blood pressure in childhood and adult life, and mortality from cardiovascular disease. BMF 1989;298:564-7.

2 Law CM, Barker DJP, Bull AR, Osmond C. Maternal and fetal influences on blood pressure. Arch Dis Child 1991; 66:1291-5.

3 Barker DJP, Osmond C, Winter PD, Simmonds SJ, Margetts $\mathrm{B}$. Weight in infancy and death from ischaemic heart disease. Lancet 1989;ii:577-80.

4 Barker DJP, Bull AR, Osmond C, Simmonds SJ. Fetal and placental size and the risk of hypertension in adult life. BMF 1990;301:259-62.

5 Osmond C, Barker DJP, Winter PD, Fall CDH, Simmonds SJ. Early growth and death from cardiovascular disease in women. $B M \mathcal{F}$ 1993;307:1519-24.

6 Law CM, de Swiet M, Fayers P, et al. Initiation of hypertension in utero and its amplification throughout life. $B M \mathcal{F}$ 1993;306:24-7.

7 Folkow B. Physiological aspects of primary hypertension. Physiol Rev 1982;62:347-504.

8 Berry CL. Hypertension and arterial development: longterm considerations. Br Heart f 1978;40:709-17.

9 Folkow B. Structure and function of the arteries in hypertension. Am Heart $\mathcal{f}$ 1987;114:938-47.

10 Berry CL, Greenwald SE. Effects of hypertension on the static mechanical properties and chemical composition static mechanical properties and chemical com
of the rat aorta. Cardiovasc Res 1976;10:437-51.

11 Berry CL, Looker T, Germain J. Nucleic acid and scleroprotein content of the developing human aorta. F Pathol 1972;108:265-74.

12 Berry CL, Gosling RG, Laogun AA, Bryan E. Anomalous iliac compliance in children with a single umbilical artery. Br Heart $\mathcal{f}$ 1978;40:709-17.

13 Safar ME, Levy BI, Laurent S, London GM. Hypertension and the arterial system: clinical and therapeutic aspects. Hypertens 1990;8(suppl 7):S113-9.

14 Greenwald SE, Denyer HT. Non invasive determination of arterial compliance by an optical method. Proceedings of the 7th International Conference on Mechanics in Medicine and Biology (Taimach, Austria 1991). Med Mazgl 1991;30:143-6.

15 Wright JS, Cruickshank JK, Kontis S, Dore C, Gosling RG. Aortic compliance measured by non-invasive Doppler ultrasound: description of a method and its reproducibility. Clin Sci 1990;78:463-8.

16 Dicke JM. Poor obstetrical outcome. In: Panerstein CJ, ed. Clinical obstetrics. Edinburgh: Churchill Livingstone, 1987:421-39.

17 Gruenwald P. Pathology of the deprived fetus and its supply line. In: Elliott KM, Knight J, eds. Size at birth Amsterdam: Elsevier, 1974:3-26.

18 Barker DJP, Godfrey KM, Osmond C, Bull A. The relation of fetal length, ponderal index and head circumfertion of fetal length, ponderal index and head ence to blood pressure and the risk of hypertension
adult life. Paediatr Perinat Epidemiol 1992;6:35-44.

19 Barker DJP, Gluckman PD, Godfrey KM, Harding JE, Barker DJP, Gluckman PD, Godfrey KM, Harding JE,
Owens JA, Robinson JS. Fetal nutrition and cardiovasOwens JA, Robinson JS. Fetal nutrition and cardio
cular disease in adult life. Lancet 1993;341:938-41.

20 Safar ME, London GM. Arterial and venous compliance in sustained essential hypertension. Hypertension 1987; 10:133-9.

21 Girerd X, Laurent S, Pannier B, Asmar R, Safar M. Arterial distensibility and left ventricular hypertrophy in patients with sustained essential hypertension. Am Hear f 1991;122:1210-4.

22 Al-Ghazali W, Chita SK, Chapman MG, Allan LD. Evidence of redistribution of cardiac output in asymmetrical growth retardation. Br $\mathcal{f}$ Obstet Gynaecol 1989;96: 697-704.

23 Rizzo G, Arduini D. Fetal cardiac function in intrauterine growth retardation. Am $\mathcal{f}$ Obstet Gynecol 1991;165: 876-82. 